International Journal of Civil Engineering and Technology (IJCIET)

Volume 9, Issue 6, June 2018, pp. 820-829, Article ID: IJCIET_09_06_095

Available online at http://www.iaeme.com/ijciet/issues.asp?JType=IJCIET \&VType=9\&IType=6

ISSN Print: 0976-6308 and ISSN Online: 0976-6316

(C) IAEME Publication

Scopus Indexed

\title{
DESIGN SERVICE OF QFD AND SPC METHODS IN THE PROCESS PERFORMANCE POTENTIAL GAIN AND CUSTOMERS VALUE IN A COMPANY
}

\author{
Yossie Rossanty, Solly Aryza, Muhammad Dharma Tuah Putra Nasution and Andysah \\ Putera Utama Siahaan
}

Universitas Pembangunan Panca Budi, North Sumatera-Indonesia

\begin{abstract}
Marketing surveys discover that the most successful organizations have to provide products or services that meet customer's requirements. The organizations can fulfill these requirements are more consistent in their competition. Quality of service is a major factor in the company's service providers faces competition in the market; therefore that is one of the companies distributing the products of convection; the company feels the need improve its services because it tends to a decline in the level of sales. The continuous communication between an organization and its consumers is necessary to reach for this state. It is a reality that the customers determine the quality of product, nor designers or production technologists. They have to design and produce the faultless product that meets all requirements of consumers. It requires the systematic approach to the integration of "Voice of Customer" into the design and production activities and received strategic decisions. The effective ways of quality assurance are based on an approach of prevention activities focused on wasted expenditure during production or services providing. This aims of paper can be assured through the continuous information obtaining about the behavior of the manufacturing process and their analysis. The aim is to have the products or provide services with required characteristics. The SPC allows finding out the significant abnormalities from the specified value of chosen product characters at the time, and it is also able to maintain the key process parameters gained by the transferring from identified and updated customer's requirements, on required and stable state in the long term. It means the process provides the products that comply with the performance quality features defined by the customers.
\end{abstract}

Keywords: SPC, QFD, PGCV, Importance Performance Analysis.

Cite this Article: Yossie Rossanty, Solly Aryza, Muhammad Dharma Tuah Putra Nasution and Andysah Putera Utama Siahaan, Design Service of Qfd and Spc

Methods in the Process Performance Potential Gain and Customers Value in a Company, International Journal of Civil Engineering and Technology, 9(6), 2018, pp. 820-829

http://www.iaeme.com/IJCIET/issues.asp?JType=IJCIET \&VType=9\&IType=6 


\section{INTRODUCTION}

Quality of service is to be one size success in ensuring satisfaction to the customer[1]-[4]. Quality's care is the overall characteristics of a product to emphasizes customer needs to fulfill customer expectations and It fits for the current used. Countless the studies for the quality of service that investigate at five-dimensional service reliability, responsiveness, assurance, empathy and tangible. First, importance-performance analysis introduced by John Martial and John C. James (1977), whereas the method potential gain customer value (PGCV) was first introduced by Willart C. Hom (1997)[5]. Methods of importance performance analysis have been used in research in Japan by Meng Seng Wong et al. (2011) to determine the response of society to Government services in Japan [6]. This study able to answer five service attributes that become the top priority for improving the quality of governance in Japan. Furthermore, PGVC method has been made in the service company. Customer analysis through indexes PGCV is a concept that is easy to analyze the customers. The ease of provides a way for importance performance diagrams to be compared in a more qualitative form detailed. The results obtained then will be used to develop strategies which were services priority system as improvements services in this company.

Based on the identification of company obtained information that nearly $50 \%$ of customers who complained the quality of service companies such as the length of time of production, the credit period is short, long in response to complaints, and so on [7][8]. For determining suitable strategies, then need to research applying the method of Importance Performance analysis and potential gain customer value simultaneously. Both approaches used integrated to obtain the best results.

\section{LITERATURE REVIEW}

\subsection{Importance Performance Analysis (IPA)}

An Importance performance analysis carried out by two aspects, the analysis of suitability and diagrams cartesian. Analysis of suitability aims to generate perception scores compare to a score of customer expectations [9]-[13] Mathematically writable.

$$
\mathrm{Tk}_{i}=\frac{x_{i}}{Y_{i}} \times 100 \%
$$

Wheres :

Tki $=$ suitability respondents

$\mathrm{Xi}=$ score customer perceptions rating

$\mathrm{Yi}=$ score customer expectations rating

The order of priority improvement through analysis of the suitability level, that given from the highest value to the lowest value. While the method diagram cartesian is used by mapping the score performance and customer expectations in the $\mathrm{x}-\mathrm{y}$ chart. The picture was divided into four parts namely quadrant i (Priority), quadrant ii (Keep achievement), quadrant iii (Low priority) and quadrant iv (Excessive). System separately area is based at the intersection of two common perception (x) and expectations (y). Attribute statements included in quadrant $\mathrm{i}$, which will be a priority major repairs. 


\subsection{Potential Gain Customer Value (PGCV)}

Several steps, namely calculate PGCV index:

\subsubsection{Achieve Customer Value (Acv)}

$\mathrm{ACV}=\mathrm{I} X \mathrm{P}$

\subsubsection{Ultimately Desire Customer Value (UDCV)}

$\mathrm{UDCV}=\mathrm{I} X \mathrm{Ps}$

Where $(\mathrm{Ps}=5)$

\subsubsection{PGCV Index}

$\mathrm{PGCV}=\mathrm{Udcv}-\mathrm{Acv}$

The order of priority is improvement through PGCV index it starts from the highest index to the lowest [14]-[16]. Once generated the order of priority of both methods, then the next step is a combined analysis of the two ways by using main priority. Correlation to the attribute test is to see how it relates to the decline in a company sale. The coefficient calculation formula relationships refer to Karl Pearson method is as follows:

$$
r=\frac{N\left(\sum x_{i} Y_{i}\right)-\left(\sum x_{i} \sum Y_{i}\right)}{\sqrt{\left[N \sum x_{i}^{2}-\left(\sum x_{i}\right)^{2}\right]\left[N \sum Y_{i}^{2}-\left(\sum Y_{i}\right)^{2}\right]}} .
$$

If the result is a quite good correlation (close to 1 or -1 ), it will proceed to design of analysis repair services. The analysis used is using a fishbone diagram.

\subsection{Statistical Process Control (SPC)}

Statistical Process Control (SPC) is the method to serves the process control with the aim of reducing the variability. The variability decrease is the key aspect of the quality improvement [17]-[20] There are two types of causes variation, assignable and standard. The assignable causes are not the regular part of the process, and we can identify them. They affect the process relatively with a great volume; it is why they demand actions that will lead in the course to their elimination. As an example of the assignable causes, it is possible to mention, e.g., machine adjustment; tools wear, measurement error, statistical error or operator error. The common causes variation effect the process all the times. Among the common causes can belong, e.g. humidity fluctuation, downgrade of plant performance and material change. The control charts are the tool of statistical process control. The fundamental objective of the control charts is to differentiate between the effect of assignable and shared causes variation in the process (figure3), whereas the assignable causes signalized in the control chart by the occurrence of points outside of the control limits, or by the various patterns and trends inside the control limits. The principle of design and plotting control charts is presented, e.g., in [5, 6].

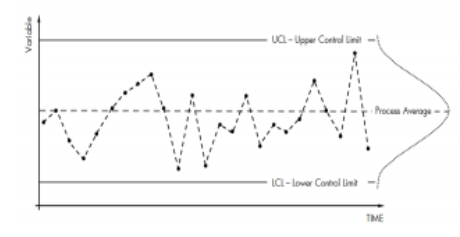

Figure 1 Control Chart. 


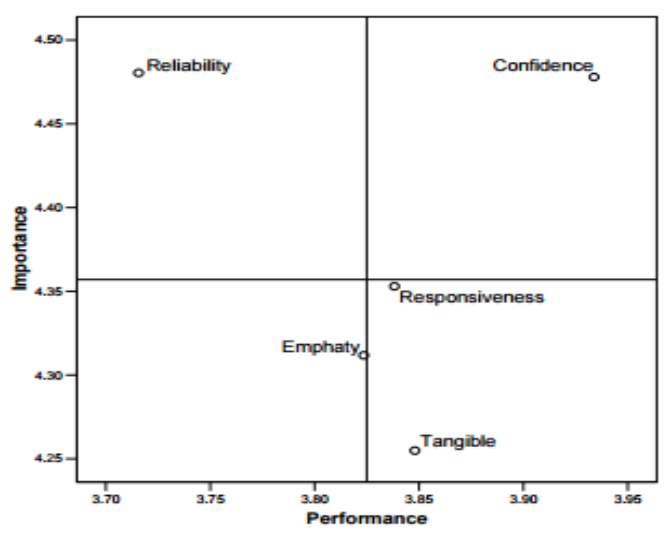

Figure 2 Each Cartesian diagram Dimensions Service

This technique based on the statistical methods is used for monitoring, controlling, analyzing and continuous improvement of the process performance, it just by the systematic eliminating of the assignable causes of process variation [6]. The SPC application generates many benefits, which concerns the process, and output quality improvement, amelioration of the communication between the process participants, possibilities of the process foreseeability, and differentiation between the assignable and shared causes, cost reduction, faster access to the problem quality solving. The lack of understanding of the potential benefits of SPC is one of the main reasons of the SPC application failure in an organization.

\subsection{The flexible using of the QFD and SPC Method}

The traditional approach to the QFD application has the exception to the benefits mentioned above the limitations. One of the lack, wherein the authors want to warn is the small relation to the traditional approach to the changing customer's requirements. It means the insufficient consideration of the complicated relationship between the floating client satisfaction and supplied product [21]-[23]. From the long-term perspective, it is desirable to update the product characteristics and process operations flexible, depending on the variable market conditions and customer's requirements. Systematic feedback is to evaluate about the customer's experiences with the product and appropriate implementation to change design and process production based on information lead to continue on customer's satisfaction with the product and the organization competitiveness.

The methodology presented further in this article lead to benefit from a combination of QFD and SPC. QFD is exploited with the aim of customer's requirements identification and transformation into the design, product, and process [24]-[26]. Also, in contradistinction to joint using of this method, described approach supposes the dynamic output updating from QFD during very production by customer's feedback. The integral part of this methodology is SPC using with the aim to maintain the essential product characteristics gained by transferring from identified and updated customer's requirements (outputs from QFD) to required and stable state in the long term. It means the process provides the products that comply with the performance quality features defined by the customers [27]-[29]. The exploitation of QFD application results for the requirements definition and continuous updating towards the suppliers is the essential prerequisite of this proposed methodology. It should lead to the provided product quality improvement and increase the customer's satisfaction.

The proposed methodology results from the continuous improvement model PDCA (Plan - Do - Check - Action). As well as, it is composed of four steps (figure 3): 
Yossie Rossanty, Solly Aryza, Muhammad Dharma Tuah Putra Nasution and Andysah Putera Utama Siahaan

1. Planning: design product and process QFD application.

2. Realization: production of the designed product control of the operations production with the help of SPC.

3. Check: analysis and data evaluating measurement of customer satisfaction and process performance evaluation.

4. Reaction: feedback QFD outputs updating.

\subsection{QFD Application}

The first step of the designed methodology, the quality planning is realized, respectively the aims and resources definition. By the contribute of QFD, the customer's requirements are identified in this phase (voice of customer) transformed into the other aspect of a product and process design and development [30].

The outputs of quality planning should have to accommodate, e.g.:

- Defined target values of technical product characteristics and its parts including acceptable tolerances;

- Defined process production including target values of decisive process operations and acceptable tolerances;

- Defined evaluation feature of process production performance;

- Defined requirements on the quality of supplies that would have been conforming with identified product characteristics and process operations;

- Established production requirements including checking activities, plant, monitoring, and measuring devices.

The product design and process review and its optimization, e.g., with using of the FMEA method should be an integral part of this step.

\subsection{Control the processes production with the help of SPC}

The designed product manufacturing should proceed in the stable conditions. The realized product is complying with the performance quality features defined by the customers. Therefore it is necessary to decrease and maintain the process variability on the required level [31]-[33]. For this purpose the statistical process control and its primary tool, the control charts are exploited here. The defined product characteristics and process operations are the key inputs for SPC and for the control charts construction that is the outputs from the previous step (QFD application). For the resulting product quality, it is appropriate that the processes at supplier organization operate under the controlled conditions too. The supplies stability shares the resulting product quality, and it will be ensured herewith. The process production must be monitored along time in the product realization [26]-[28]. The collected relevant data are analyzed and evaluated in the next step.

\subsection{Measurement of Customer Satisfaction and Process Performance Evaluation}

The continuous measurement of customer satisfaction and identify changes in their requirements are necessary for another product improvement and the customer's satisfaction raising [37]-[39]. Management should recognize that there are many sources of customerrelated information analyze and use this information for improving the performance of the organization. It is an important measurement of process performance, according to the defined features and significant corrective actions (in the case of underperformance) that would have reflected in the process, and provided product improvement. One of the possibilities is the 
methods of capability evaluation according to the product characteristics and process operations [7], [40]-[42].

\subsection{QFD Outputs Updating}

The measurement of customer satisfaction results and identified changes in their requirements should show up in the matrix diagrams updating. It could cause the changes in the key product characteristics and process operations and consequently in the strategic decisions for the others direction of process production. The process like this is then more or less managed by the customers and its requirements. The contributes to the success and competitiveness rising of the organization [43]-[45].

\section{DISCUSSION}

\subsection{Example of the methodology application}

In this chapter is shown a simple illustration of the presented method using the combination of QFD and SPC methods. Concretely, it will outline the two steps firstly of the methodology. The results of QFD application along with the steel compression - molded wheel design are used. Due to the know-how observed only selected information of this request that will be presented.

\section{Step 1: QFD application}

Identification of customer's requirements upon this the product was the first step. These requirements were transformed in turn to the product quality characteristics and its parts into the process operations and production requirements. According to customer's evaluation, among the conditions with the highest relative weight belongs to:

- car wheel holding size according to the drawing;

- convenient car wheel life;

- Rim air-proofs, and others.

Seven fundamental customer's requirements in some were defined there. After the gradual transformation of requirements, the 22 wheel technical characteristics and 52 process operations of motor production further identified. The engine components are assigned to two parts of these: a steel compression - molded wheel composed - disk and rim. The special importance and target values of individual product characteristics and process operations are evaluated. The target values were the outputs from QFD method application, and after review, the product and process were prepared to the steel compression - molded wheel realization. The part of the house of quality for the most important requirements and technical product characteristics of the steel compression - the molded wheel is shown in figure 3 . The result of technical importance and target values of the compression - molded steel wheel is mentioned in table 1 .

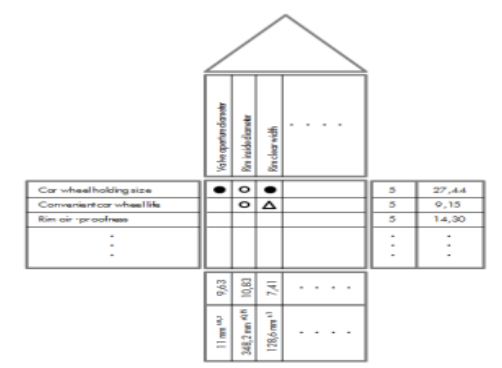

Figure 3 Part of the House of Quality for the steel compression-molded wheel. 
Yossie Rossanty, Solly Aryza, Muhammad Dharma Tuah Putra Nasution and Andysah Putera Utama Siahaan

Table 1 Selected Steel Compression-Molded Wheel Characteristics \& Target Values

\begin{tabular}{|l|c|c|}
\hline \multicolumn{1}{|c|}{ Product characteristics } & $\begin{array}{c}\text { Technical } \\
\text { importance }\end{array}$ & Target values \\
\hline Valve aperture diameter & 9,63 & $11 \mathrm{~mm}{ }^{ \pm 0,2}$ \\
\hline Rim inside diameter & 10,83 & $348,2 \mathrm{~mm}{ }^{ \pm 0,15}$ \\
\hline Rim clear widht & 7,41 & $128,6 \mathrm{~mm}$ \\
\hline$\ldots$ & $\ldots$ & $\ldots$ \\
\hline
\end{tabular}

By the key technical steel compression - molded wheel characteristics knowledge and its process production, the important supplies parameters from the subcontractors are defined in this step. One of the deciding parameters was the steel quality provided in the coils for instance. Qualities of supplied steel (settings such as the elasticity, strength and steel chemistry) have a cardinal impact on the resulting quality of the wheel and especially on the one of customer's requirement fulfilled - the useful car wheel life.

\section{Step 2: Process control with the help of control charts}

The single steel compression - molded wheel production proceed in the controlled conditions, whereas the statistical process control has exploited. A control performed according to the key product characteristics and process operations that are the outputs of the previous step (Table.I). It means that for the key product features and process operations the control charts were constructed and analyzed continuously. In the case of the assignable causes variation activity, the actions to the elimination of these undesirable influences are proposed, and there were carried out the corresponding interventions into the process production. Herewith it was attained by the stable process, accordant with the customer's requirements. The next steps 3 and 4 of the methodology then represent the measurement and monitoring of customer satisfaction as well as the changes in their steel compression - molded wheel requirements. Every change in the client satisfaction and their needs have to implement into the matrix diagrams applied to QFD method. The updating outputs from this approach have to be transferred into the process production, respectively to the SPC. It gets to the change in the relative weight of the requirements by the improved ability to fulfill the individual needs or vice versa. It reflects the modification of the key technical product characteristics or in discovering new requirement. It means the definition of new technological product feature, etc.

\section{CONCLUSION}

The indispensable condition of the organization success is a fast and suitable fulfillment of the customer's requirements. Therefore it is important to design the product and control the process in compliance with the client's needs and expectations. It is possible to achieve through the proposed methodology (combination of QFD and SPC methods) and the exploitation of the continuous feedback of the customer's satisfaction measurement.

\section{ACKNOWLEDGMENT}

The authors gratefully acknowledge the financial support from Universitas Pembangunan Panca Budi, and we would like to thank the anonymous reviewers for their comment on this article. 
Design Service of Qfd and Spc Methods in the Process Performance Potential Gain and Customers Value in a Company

\section{REFERENCES}

[1] S. Haryati, A. Ikhwan, D. Arisandi, Fadlina, and A. P. U. Siahaan, "Quality Assurance in Knowledge Data Warehouse," Int. J. Sci. Res. Sci. Technol., vol. 3, no. 6, p. 239-242], 2017.

[2] M. D. T. P. Nasution and Y. Rossanty, "Country of Origin as a Moderator of Halal Label and Purchase Behavior,” J. Bus. Retail Manag. Res., vol. 12, no. 2, pp. 194-201, 2018.

[3] Y. Rossanty, D. Hasibuan, J. Napitupulu, M. D. T. P. Nasution, and R. Rahim, "Composite performance index as decision support method for multi case problem," Int. J. Eng. Technol., vol. 7, no. 2.29, pp. 33-36, 2018.

[4] S. Aryza, M. Irwanto, Z. Lubis, A. P. U. Siahaan, R. Rahim, and M. Furqan, "A Novelty Design of Minimization of Electrical Losses in A Vector Controlled Induction Machine Drive," in IOP Conference Series: Materials Science and Engineering, 2018, vol. 300, no. 1.

[5] E. Rebentisch, G. Schuh, M. Riesener, M. Gerlach, and P. Zeller, "Determination of a Customer Value-oriented Product Portfolio," Procedia CIRP, vol. 50, pp. 82-87, 2016.

[6] M. Wong, H. Nishimoto, Y. Nishigaki, and J. Stephen, "Use of Satisfaction-Satisfaction Matrix (SSM) to evaluate e-government services from the perspective of Japanese citizens and government service providers," in ACIS 2013: Information systems: Transforming the Future: Proceedings of the 24th Australasian Conference on Information Systems, 2013, pp. 1-10.

[7] H. M. Ritonga, H. A. Hasibuan, and A. P. U. Siahaan, "Credit Assessment in Determining the Feasibility of Debtors Using Profile Matching," Int. J. Bus. Manag. Invent, vol. 6, no. 1, pp. 73-79, 2017.

[8] R. Wulandari, "Do Credit Channel And Interest Rate Channel Play Important Role In Monetary Transmission Mechanism In Indonesia?: A Structural Vector Autoregression Mode," in Procedia-Social and Behavioral Sciences, 2012, pp. 557-563.

[9] Z. M. Ali, Munira Ismail, N. R. M. Suradi, and A. S. Ismail, "Importance-performance analysis and Customer Satisfaction Index for express bus services," in 2009 World Congress on Nature \& Biologically Inspired Computing (NaBIC), 2009, pp. 590-595.

[10] H. P. Ferreira and P. O. Fernandes, "Importance-performance Analysis Applied to a Laboratory Supplies and Equipment Company," Procedia Comput. Sci., vol. 64, pp. 824831, 2015.

[11] Y. Rossanty and M. D. T. P. Nasution, "Information Search and Intentions to Purchase: The Role of Country of Origin Image, Product Knowledge, and Product Involvement," J. Theor. Appl. Inf. Technol., vol. 96, no. 10, pp. 3075-3085, 2018.

[12] M. Dharma Tuah Putra Nasution et al., "Decision Support Rating System with Analytical Hierarchy Process Method,” Int. J. Eng. Technol., vol. 7, no. 2.3, pp. 105-108, Mar. 2018.

[13] A. P. U. Siahaan and R. Rahim, "Dynamic Key Matrix of Hill Cipher Using Genetic Algorithm,” Int. J. Secur. It's Appl., vol. 10, no. 8, pp. 173-180, Aug. 2016.

[14] P. Hynninen and M. Kauppinen, "A/B testing: A promising tool for customer value evaluation," in 2014 IEEE 1st International Workshop on Requirements Engineering and Testing (RET), 2014, pp. 16-17.

[15] J. Zhao, R. Shi, L. Sai, X. Huang, and Y. Su, "Comprehensive genetic algorithm for ab initio global optimisation of clusters," Mol. Simul., vol. 42, no. 10, pp. 809-819, Jul. 2016.

[16] R. Rahim et al., "Searching Process with Raita Algorithm and its Application," J. Phys. Conf. Ser., vol. 1007, no. 1, pp. 1-7, 2018. 
[17] M. S. Bereman et al., "Implementation of Statistical Process Control for Proteomic Experiments Via LC MS/MS,” J. Am. Soc. Mass Spectrom., vol. 25, no. 4, pp. 581-587, Apr. 2014.

[18] Xianghui Ning, Yanfen Shang, and Fugee Tsung, "Statistical process control techniques for service processes: a review," in 2009 6th International Conference on Service Systems and Service Management, 2009, pp. 927-931.

[19] J. C. Metzler, "Implementation of Statistical Process Control: A people oriented approach," in 1985 EIC 17th Electrical/Electronics Insulation Conference, 1985, pp. 320 324.

[20] R. Rahim et al., "Combination Base64 Algorithm and EOF Technique for Steganography,” J. Phys. Conf. Ser., vol. 1007, no. 1, pp. 1-5, 2018.

[21] M. Kelblerova and D. Vykydal, "Application of QFD and SPC methods in the processes of design and products manufacturing," in 2011 12th International Carpathian Control Conference (ICCC), 2011, pp. 181-186.

[22] C. Chang, "Quality Function Deployment (QFD) processes in an integrated quality information system," Comput. Ind. Eng., vol. 17, no. 1-4, pp. 311-316, Jan. 1989.

[23] R. Meiyanti, A. Subandi, N. Fuqara, M. A. Budiman, and A. P. U. Siahaan, "The Recognition of Female Voice Based on Voice Registers in Singing Techniques in RealTime using Hankel Transform Method and Macdonald Function,” J. Phys. Conf. Ser., vol. 978, no. 1, pp. 1-6, 2018.

[24] C. Adiano and A. V. Roth, "Beyond the House of Quality: Dynamic QFD," Benchmarking Qual. Manag. Technol., vol. 1, no. 1, pp. 25-37, Apr. 1994.

[25] J. Simota and J. Tupa, "Implementation of SPC methodology to service processes," in Proceedings of the 2014 37th International Spring Seminar on Electronics Technology, 2014, pp. 298-302.

[26] K. A. Ibrahim and M. T. Tham, "Towards active statistical process control," in Proceedings of 1995 American Control Conference - ACC'95, vol. 3, pp. 2234-2238.

[27] Z. Tharo and A. P. U. Siahaan, "Profile Matching in Solving Rank Problem," IOSR J. Electron. Commun. Eng., vol. 11, no. 5, pp. 73-76, 2016.

[28] R. Linker, "Extension of statistical process control (SPC) methodology to dynamic systems controlled via output feedback," in 2008 IEEE Conference on Cybernetics and Intelligent Systems, 2008, pp. 482-486.

[29] M. F. Chen and M. C. Huang, "SPC precaution system," in 2004 Semiconductor Manufacturing Technology Workshop Proceedings (IEEE Cat. No.04EX846), pp. 186189.

[30] J. B. ReVelle, J. W. Moran, and C. A. Cox, The QFD Handbook. New York: John Wiley \& Sons, Inc., 1998.

[31] L. R. Wang and H. Rowlands, "A fuzzy logic application in SPC evaluation and control," in 1999 7th IEEE International Conference on Emerging Technologies and Factory Automation. Proceedings ETFA '99 (Cat. No.99TH8467), vol. 1, pp. 679-684.

[32] I. Madanhire and C. Mbohwa, "Application of Statistical Process Control (SPC) in Manufacturing Industry in a Developing Country," Procedia CIRP, vol. 40, pp. 580-583, 2016.

[33] H. A. Hasibuan, R. B. Purba, and A. P. U. Siahaan, "Productivity Assessment (Performance, Motivation, and Job Training) using Profile Matching," Int. J. Econ. Manag. Stud., vol. 3, no. 6, pp. 73-77, 2016.

[34] B. Nie, Liu Qiang, Liao Dan, and Ding Jing, "Statistical Process Control based on state space model," in The 2nd International Conference on Information Science and Engineering, 2010, pp. 1-8. 
[35] J. W. Sinn, "Introduction and overview of statistical process control," in Proceedings of Electrical/Electronics Insulation Conference, pp. 729-736.

[36] B. Thomas, "Statistical process control for frequency control," in 44th Annual Symposium on Frequency Control, pp. 285-293.

[37] M. Bražènas, G. Horváth, and M. Telek, "Parallel algorithms for fitting Markov arrival processes," Perform. Eval., vol. 123-124, pp. 50-67, Jul. 2018.

[38] E. G. Amparore and S. Donatelli, "Efficient model checking of the stochastic logic CSL TA,” Perform. Eval., vol. 123-124, pp. 1-34, Jul. 2018.

[39] Mesran, R. K. Hondro, M. Syahrizal, A. P. U. Siahaan, R. Rahim, and Suginam, "Student Admission Assessment using Multi-Objective Optimization on the Basis of Ratio Analysis (MOORA)," J. Online Jar. COT POLIPD, vol. 10, pp. 1-6, 2017.

[40] P. A. Davis, "QFD-a structured approach to understanding the voice of the customer," in Proceedings of 1995 IEEE Applied Power Electronics Conference and Exposition APEC'95, pp. 245-251.

[41] L. Hong, W. Wang, and H. Zhao, "A service quality management approach based on QFD," in ICSSSM12, 2012, pp. 11-14.

[42] A. P. U. Siahaan et al., "Combination of Levenshtein Distance and Rabin-Karp to Improve the Accuracy of Document Equivalence Level," Int. J. Eng. Technol., vol. 7, no. 2.27, pp. 17-21, 2018.

[43] A.-Y. Jiao and L. Zhou, "Performance Evaluation Research of Service Quality Based on Process," in 2008 4th International Conference on Wireless Communications, Networking and Mobile Computing, 2008, pp. 1-4.

[44] A. Lodhi, V. Koppen, S. Wind, G. Saake, and K. Turowski, "Business Process Modeling Language for Performance Evaluation," in 2014 47th Hawaii International Conference on System Sciences, 2014, pp. 3768-3777.

[45] Mesran, K. Tampubolon, R. D. Sianturi, F. T. Waruwu, and A. P. U. Siahaan, "Determination of Education Scholarship Recipients Using Preference Selection Index," Int. J. Sci. Res. Sci. Technol., vol. 3, no. 6, pp. 230-234, 2017.

[46] Ajit Kumar Singh and A.M. Rawani, Application of QFD in Education Sector: A Review, International Journal of Mechanical Engineering and Technology, 9(3), 2018, pp. 592599.

[47] Dr. R. Dillibabu, Sangeetha. A and L. Sudha, Application of SQFD Model in Software Testing Environment, International Journal of Industrial Engineering Research and Development (IJIERD), Volume 4, Issue 3, September - December (2013), pp. 50-60.

[48] Dillibabu R, Krishnaiah K, Baskaran R, Development and Application of SQFD Model for an Innovative Embedded Software Product - A Case Study, International Journal of Industrial Engineering Research and Development (IJIERD), Volume 2 Issue 1, May October (2011), pp. 15-45.

[49] Jandel S Yadav and Dr. Anshul Gangele, Optimization of Product Characteristics in QFD using Optimization Techniques: a Comparative Study, International Journal of Mechanical Engineering and Technology 8(11), 2017, pp. 797-811.

[50] Thirumanas K R and K C Joseph, Service Quality Analysis and Improving Customer Satisfaction in Automobile Service Industry Using QFD, International Journal of Industrial Engineering Research and Development (IJIERD), Volume 4, Issue 1, January April (2013), pp. 41-51 